
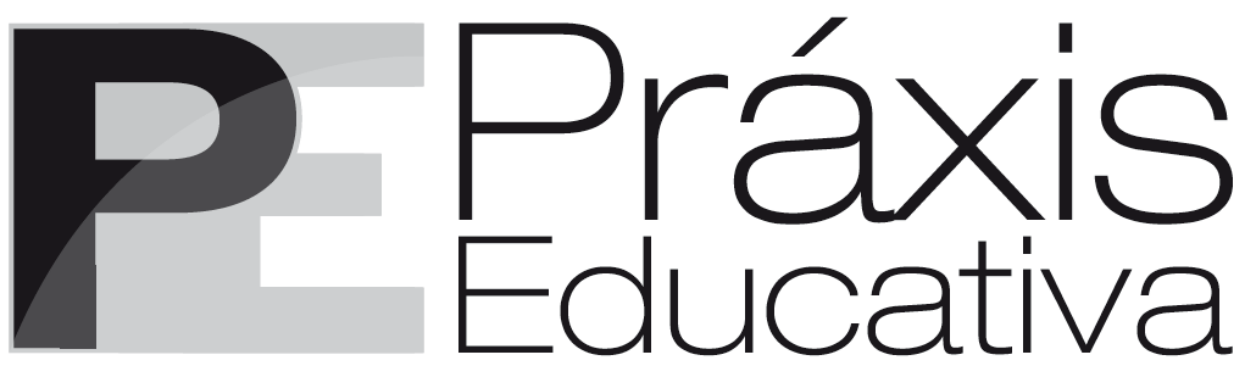

ISSN 1809-4309 (Versão online)

DOI: 10.5212/PraxEduc.v.12i2.0014

\title{
Esporte paralímpico: difícil inclusão, incorporação tecnológica, corpos competitivos $^{*}$
}

\section{Paralympic sport: difficult inclusion, technological incorporation, competitive bodies}

\section{Deporte paraolímpico: difícil inclusión, incorporación tecnológica, cuerpos competitivos}

\author{
Danielle Torri $^{* *}$ \\ Alexandre Fernandez $\mathrm{Vaz}^{* * *}$
}

Resumo: Neste artigo, analisa-se, de forma exploratória, o esporte em sua versão paraolímpica, com foco nos discursos que valorizam práticas que seriam de superação e inclusão, tomando como situações exemplares algumas representações sobre o fenômeno. Procurou-se desenvolver dois tópicos: a composição entre rendimento x estética mediada pela técnica, a partir do conceito de estética da presença, proposto por Hans Ulrich Gumbrecht; e a aproximação entre o esporte olímpico e paralímpico dada pela incorporação tecnológica. Por fim, apontam-se caminhos ainda pouco percorridos na análise do fenômeno, com implicações no que o esporte paralímpico e também o convencional podem oferecer como expressão social do tempo atual.

Palavras-chave: Esporte paralímpico. Estética. Deficiência.

Abstract: In this paper, we analyze, in an exploratory way, the Paralympic sport. Our focus is on the speeches that value practices that would concern overcoming and inclusion, taking exemplary situations as some representations about the phenomenon. We sought to develop two topics: the composition between performance versus aesthetics mediated by technique, from the concept of aesthetic of presence, proposed by Hans Ulrich Gumbrecht, and the approximation between the Olympic and Paralympic sport

\footnotetext{
* O trabalho é resultado parcial do Programa de Pesquisas Teoria Críticas, Racionalidades e Educação (IV), financiado pelo Conselho Nacional de Desenvolvimento Científico e Tecnológico (CNPq) (Proc. n. 443201/2015-3 e 308297/2013-0). Agradecemos a Gisele Carreirão Gonçalves e a Michelle Carreirão Gonçalves pela leitura, pelas críticas e pelas sugestões a versões anteriores deste trabalho, bem como ao parecer anônimo de Práxis Educativa, responsáveis por minimizar os equívocos e as insuficiências do artigo.

** Doutoranda em Educação do Programa de Pós-Graduação em Educação da Universidade Federal de Santa Catarina (UFSC). Bolsista da Coordenação de Aperfeiçoamento de Pessoal de Nível Superior (CAPES). E-mail: $<$ danielletorri@yahoo.com.br>.

*** Professor do Programa de Pós-Graduação em Educação e do Programa de Pós-Graduação Interdisciplinar em Ciências Humanas, da Universidade Federal de Santa Catarina (UFSC); Pesquisador CNPq. E-mail: <alexfvaz@uol.com.br>.
} 
given by the technological incorporation. Finally, we point out ways still poorly covered in the analysis of the phenomenon, with implications of what the Paralympic and also the conventional sport can offer as social expression of current times.

Keywords: Paralympic sport. Aesthetics. Disability.

Resumen: En este artículo se analiza, de manera exploratoria, el deporte en su versión paraolímpica, con foco en los discursos que valoran las prácticas que serían de superación e inclusión, tomando como situaciones ejemplares algunas representaciones del fenómeno. Intentamos desarrollar dos tópicos: la composición entre rendimiento y estética mediada por la técnica, a partir del concepto de estética de la presencia, de Hans Ulrich Gumbrecht; y el acercamiento entre el deporte olímpico y paraolímpica, dada por la incorporación tecnológica. Finalmente, se puntuaron caminos todavía poco explorados en el análisis del fenómeno, con implicaciones de lo que las dos versiones del deporte pueden aportar como expresión social del tiempo actual.

Palabras-clave: Deporte Paraolímpico. Estética. Deficiencia.

\section{Corpos e esportivização}

O Esporte é um fenômeno social moderno, frequentemente visto como expressão da eficiência humana, daquele que ultrapassa a dor e as adversidades, do vencedor. Os feitos dos atletas superam imaginariamente a condição individual, sendo, por vezes, considerados conquistas da humanidade, mesmo que o recorde tenha sido obtido por um ser humano em particular (VAZ, 1999). Gênero, geração, nacionalidade, etnia, ter ou não uma deficiência, entre tantas outras possibilidades, balizam e fazem oscilar a individualidade e a universalidade esportiva.

Perfeição e performance são obtidas a partir de um domínio corporal muito intenso, representado pelo treinamento esportivo. Este opera, paradoxalmente, na destruição e na violência sobre o corpo, pois, para que a performance esportiva de alto rendimento aconteça, é preciso tomá-la como objeto, matéria moldável que pode ser manipulada em nome de seu aperfeiçoamento.

Se o fenômeno esportivo é um dos importantes veículos no processo de potencialização corporal, é de destacar-se que a Educação Física, como disciplina escolar, também participa desse processo, já que aquele lhe é conteúdo pedagógico privilegiado. Ela, dentre outras formas de treinamento corporal, como aquelas praticadas nas academias e nos clubes, reforça a ideia de que, no contemporâneo, educar o corpo parece ser o mesmo que conformá-lo a partir de práticas específicas com vistas a um padrão de normalidade que dita quanto ele pode medir, pesar, com quem e com o que se parecer.

Neste artigo, fruto de uma pesquisa ainda em fase inicial, analisamos, de forma exploratória, aspectos da versão paralímpica do esporte, perguntando sobre o que ele pode dizer sobre a sociedade contemporânea, em suas formas de expressão corporal. Procuramos, com isso, colaborar para a construção de uma perspectiva crítica sobre esse fenômeno.

$\mathrm{O}$ artigo estrutura-se em três partes, antes das considerações finais. Apresentamos, inicialmente, uma breve contextualização sobre o fenômeno, com foco no discurso que valoriza práticas que seriam de superação e de inclusão, que emergem em reportagens de situações exemplares como representações sobre o esporte paralímpico. Em seguida, procuramos desenvolver dois tópicos, a composição entre rendimento x estética mediada pela técnica e a aproximação entre o esporte olímpico e paralímpico, dada, principalmente - e com respectivas

Práxis Educativa, Ponta Grossa, v. 12, n. 2, p. 536-550, maio/ago. 2017 Disponível em: <http://www.revistas2.uepg.br/index.php/praxiseducativa> 
especificidades - pela incorporação tecnológica. Finalizamos apontando caminhos ainda pouco percorridos na análise do fenômeno, e alguns planos em que o esporte paralímpico, mas também sua versão olímpica, podem se colocar como expressão social de nosso tempo.

\section{Esporte paralímpico: expectativas de inclusão e de superação}

Os Jogos Paralímpicos, competição que reúne um conjunto de modalidades esportivas para pessoas com deficiência, acontecem logo após a realização dos Jogos Olímpicos, na mesma cidade. O esporte paralímpico foi inicialmente criado para a reabilitação de soldados severamente feridos em guerra.

Em 1944, Ludwig Guttmann, médico alemão radicado na Inglaterra, foi encarregado pelo governo inglês, do primeiro ministro Winston Churchill, a criar um centro especializado em lesões da coluna - o Stoke Mandeville Hospital. Nele, o esporte recreacional era utilizado para a reabilitação, e a participação em competições era incentivada. Nos Jogos Olímpicos de Londres, em 1948, 16 militares - homens e mulheres com algum tipo de lesão - participaram da competição de tiro com arco junto aos outros inscritos. Em 1952, holandeses inscreveram-se nos jogos do referido hospital, dando status internacional à competição - primeiro passo para que, em 1960, se organizasse os primeiros Jogos Paralímpicos ${ }^{1}$. Originalmente adaptado do esporte convencional, com o tempo outras modalidades foram incorporadas ao desporto para pessoas com deficiência, como é o caso do goalball, modalidade desenvolvida para a prática de pessoas com deficiência visual.

O desporto Paralímpico cresce, em grande medida, com o objetivo da inserção de pessoas com deficiência no mundo esportivo, marca de sua participação social mais ampla. Essa inclusão consiste na incorporação de corpos que se encontram fora da normatividade (física, fisiológica, social) estipulada e reafirmada pelo esporte. Pessoas com deficiência têm sido, no entanto, convidadas a tomar parte das práticas esportivas, oferecendo e auferindo legitimidade e prestígio às modalidades esportivas por elas praticadas, por meio dos discursos da inclusão e da superação ${ }^{2}$, que também fazem parte do esporte convencional (GONÇALVES; ALBINO; VAZ, 2009).

Embora o discurso da superação seja constante quando se escreve sobre os paralímpicos, estes não têm a mesma percepção e chegam a contestar a forma como são vistos, arguindo que a superação é necessária tanto para atletas com deficiência quanto para os que não a possuem. A atleta Rosinha dos Santos, da equipe brasileira de atletismo presente nos Jogos Mundiais em Toronto, no Canadá, disse à TV Brasil "estar cansada" de ouvir o discurso de que o esporte é "uma terapia de superação". A atleta criticou:

As pessoas precisam enxergar que aqui o atleta com deficiência não é um coitadinho. Aqui, não tem nenhum atleta coitadinho, não. Ninguém aqui tá saindo de casa para conhecer pessoas e superar. Aqui tem atleta de alto rendimento. Igual aos atletas convencionais. O mesmo hino nacional que toca nas Olimpíadas, toca aqui. Todo o atleta com deficiência ou não tem que se superar. Aqui não é só superação. (GARRITANO; RICHARD, 2015, s/p).

\footnotetext{
${ }^{1}$ Disponível em: < http://www.rio2016.com/noticias/a-historia-dos-jogos-paralimpicos-da-reabilitacao-de-soldadosferidos-na-segunda-guerra-a-c >. Acesso em: 7 mar. 2016.

2 No esporte, o discurso da superação é utilizado para adjetivar o esforço físico e psicológico dos atletas nos treinamentos e nas competições. Refere-se à importância de os atletas persistirem e perseverarem frente às dificuldades impostas ao longo da carreira. A esse resultado na solução de problemas é dado o nome de "superação". O discurso de exaltação das dificuldades, da resiliência é exaltado e comemorado, frequentemente, como se os atletas fossem heróis.
}

Práxis Educativa, Ponta Grossa, v. 12, n. 2, p. 536-550, maio/ago. 2017 Disponível em: <http://www.revistas2.uepg.br/index.php/praxiseducativa > 
Atualmente, as Paralimpíadas arregimentam outros praticantes para além dos seriamente feridos na guerra ${ }^{3}$, seu público inicial. No Brasil, grande parte desses atletas são os lesados pelo trabalho, como policiais ${ }^{4}$; e acidentados de trânsito, com destaque, em algumas modalidades como o voleibol sentado (GONÇALVES; ALBINO; VAZ, 2007). Em alguns países, como a Colômbia, os praticantes são frequentemente pessoas que apresentam sequelas por ferimentos de ações violentas da guerra civil e do narcotráfico. E, para além das modalidades para os que possuem deficiências físicas, há algumas que integram outros tipos de deficiência, como as sensoriais (fundamentalmente também corporais, aliás), nas quais competem atletas que apresentam deficiência em alguns dos cinco sentidos, notadamente, nesse caso, visual ${ }^{5}$.

Os Jogos Paralímpicos são organizados com os mesmos princípios de seu irmão - os Jogos Olímpicos. Posições de destaque nos rankings das modalidades são exigidas, e, da mesma forma que nos Jogos Olímpicos, há divisões internas, categorias para cada deficiência, com classificação do grau de comprometimento. Desse modo, o discurso do caráter inclusivo do esporte paralímpico perde força, uma vez que se mostra tão segregador quanto àquele que lhe serve de modelo, pois, apesar de ser praticado por atletas com diagnóstico de deficiência, nem todos que gostariam de competir em uma Paralimpíada - ou ainda que possuem diagnóstico sobre sua condição - chegam a alcançá-la, visto que, do mesmo modo que seu grande modelo, ela acolhe somente aqueles que se destacam e atingem os índices. Dessa forma, os Jogos Paralímpicos corroboram o mesmo discurso esportivo, do desempenho e da potencialização corporal enunciados pelos Jogos Olímpicos.

A relação entre olimpismo e paralimpismo é de fluxo e movimento, mas com especificidades, como antes colocado. Se, por um lado, a radical separação por deficiência e grau de comprometimento se coloca; por outro, há atletas paralímpicos que procuram o esporte olímpico. Esse foi o caso do atleta sul africano de atletismo, Oscar Pristorius, que, mesmo após quebrar uma série de recordes no atletismo e ganhar todos os títulos possíveis no paradesporto, teve dificuldade para conseguir participar dos Jogos Olímpicos. A alegação era de que sua prótese lhe poupava energia, fazendo-o auferir uma vantagem vedada aos demais atletas ${ }^{6}$. Entretanto, após uma série de polêmicas e batalhas judiciais, o atleta conseguiu que se aceitasse que elas não lhe traziam vantagem em relação aos outros e participou das Olimpíadas de Londres, ficando, no entanto, fora do pódio ${ }^{7}$.

Uma discussão semelhante voltou a acontecer recentemente. Um atleta de salto em distância alemão, Markus Rehm, saltou 8,40 metros, obteve o novo recorde mundial paralímpico pela classe T44 ${ }^{8}$, em Doha, Catar, em outubro de 2015. Com essa marca, Rehm teria alcançado a

\footnotetext{
3 Disponível em: <http://pan.uol.com.br/noticias/2015/08/13/eua-usam-parapan-para-ajudar-ex-militaresmutilados-em-guerras.htm>. Acesso em: 13 ago. 2015.

4 Disponível em: <http://globoesporte.globo.com/programas/esporte-espetacular/noticia/2015/10/policiaisacidentados-se-recuperam-e-tornam-se-paratletas-medalhistas.html>. Acesso em: 11 out. 2015.

5 Destacamos que os deficientes auditivos não tomam parte nas disputas paralímpicas, possuindo, desde 1924, sua própria competição, as Surdolimpíadas. A próxima acontecerá em 2017, em Samsun, na Turquia. São disputadas modalidades olímpicas, paralímpicas e outras que não estão no programa das duas competições. O Comitê Paralímpico Internacional entende que os surdos podem tomar parte das disputas convencionais.

${ }^{6}$ Voltaremos a essa discussão mais à frente no texto.

7 Disponível em: <http://olhardigital.uol.com.br/noticia/blade-runner-correra-nas-olimpiadas-de-londres/27571>. Acesso em: 8 mar. 2016.

8 Os competidores paralímpicos pertencem a seis diferentes grupos: Atleta com paralisia cerebral; Atleta com lesão medular/poliomelite; Atleta com amputação; Atleta com deficiência visual; Atleta com deficiência intelectual; "Les autres" (que inclui todos os atletas com alguma deficiência de mobilidade não incluída nos grupos anteriores). A preocupação é sempre encontrar um sistema que garanta o princípio de igualdade de condições na disputa, princípio já colocado no esporte convencional e que levaria, assim se supõe, a resultados justos no final das competições
}

Práxis Educativa, Ponta Grossa, v. 12, n. 2, p. 536-550, maio/ago. 2017 Disponível em: <http://www.revistas2.uepg.br/index.php/praxiseducativa> 
medalha de ouro nas Olimpíadas de Pequim/2008 e Londres/2012. O atleta foi, no entanto, impedido pela Federação Internacional de Atletismo (IAAF) de competir no Brasil nas Olimpíadas em 2016 porque a Federação Internacional de Atletismo Amador (IAAF) entende que competidores paralímpicos poderiam levar vantagem em relação aos Olímpicos, sendo beneficiados pelo uso da prótese.

O discurso da inclusão, que incita os atletas a procurarem o esporte e estarem "incluídos" na sociedade, mas lhes dificulta a participação entre os sem deficiência, apresenta-se paradoxal. Eles devem competir apenas entre si. Ou seja, estar incluídos, mas distinguidos, apenas entre os próprios atletas com deficiência.

Foi nos últimos anos que a visibilidade da Paralimpíadas aumentou no Brasil. Em parte, porque os com deficiência se tornam mais visíveis socialmente, algo expresso, por exemplo, pelas leis que versam sobre a inclusão" mas também porque o País vem obtendo bons resultados nessas competições. A primeira medalha paralímpica brasileira aconteceu em Toronto em 1976. Em 1996, em Atlanta, o Brasil ficou na $37^{\circ}$ posição; em Sidney, 2000, em 24 $4^{\circ}$ em Atenas, 2004, em 14; em Pequim, 2008, em $9^{\circ}$; e em Londres, 2012, em $7^{\circ}$ lugar geral. Nosso País sediou uma edição dos Jogos Pan-Americanos, em 2007, e se prepara para sediar os Jogos Olímpicos e Paralímpicos no ano de 2016. A expectativa de colocação geral em 2016 é de um inédito quinto lugar, algo visto como possível dada a escalada nos resultados brasileiros.

O sucesso nos Jogos Paralímpicos de atletas brasileiros tem proporcionado grande visibilidade para alguns deles, como o nadador Daniel Dias, detentor de 15 medalhas paralímpicas. O atleta conta com grande assessoria, site para as pessoas o conhecerem e foi embaixador das Paralimpíadas Escolares em $2015^{10}$. Os não tão conhecidos, como o nadador catarinense Talisson Glock e a corredora Verônica Hipólito, apontados como atletas com grandes chances de medalhas em 2016, representam o Sesi/São Paulo e contam com patrocínio de grandes empresas, como a Nike, a Caixa Econômica Federal e a Petrobrás, além de bolsas dos Governos Federal e Estadual. Eles fazem parte da chamada geração pós-Londres, que se prepara para lutar pela primeira medalha em Jogos Paralímpicos (MEINICKE, 2015).

Para além do discurso da superação, comum ao esporte convencional e ao seu correlato paralímpico, outras características apontam a possibilidade de aproximação entre os dois

(MARQUES et al., 2009). Assim, é possível observar que, da mesma maneira que os atletas de esportes tradicionais, separados em categorias e pesos nas lutas ou ainda por gênero, os atletas paralímpicos são também agrupados em categorias de acordo com o comprometimento apresentado, não só para poderem competir entre si, mas também para participarem do sistema esportivo que opera por classificação, mensuração, normalização e regras e, também, de comparações entre os atletas - tudo isso medular na dinâmica dos esportes (BROHM, 1978).

${ }^{9}$ Lei $\mathrm{n}^{\mathrm{o}}$ 13.146, de 6 de julho de 2015, que institui a Lei Brasileira de Inclusão da Pessoa com Deficiência (Estatuto da Pessoa com Deficiência). Ou, ainda, as que tratam especificamente da inclusão de crianças com deficiência na escola, como a Lei 7.853, de 1989, que dispõe sobre o apoio às pessoas portadoras de deficiência e sua integração social; Estatuto da Criança e do Adolescente, de 1990; Declaração de Salamanca, de 10 de junho de 1994, sobre princípios, políticas e práticas na área das necessidades educacionais especiais; Capítulo da LDB, de 1996, sobre a Educação Especial. E, para o esporte, a Lei Agnelo Piva de 2001, que repassa recursos das loterias para os comitês Olímpicos e Paralímpicos.

10 As Paralimpíadas Escolares tiveram sua edição mais recente na capital do Rio Grande do Norte, com a participação de mais de 700 atletas de 24 Estados, do Distrito Federal, além de convidados do Reino Unido. Trata-se de uma competição organizada pelo Comitê Paralímpico Brasileiro (CPB) que reúne estudantes com deficiência e que disputaram oito modalidades: atletismo, natação, bocha, futebol de sete, tênis de mesa, tênis em cadeira de rodas, judô e goalball. No site do comitê Paralímpico, disponível em uma rede social, encontra-se a seguinte frase: "É um evento que tem objetivos muito claros: formar futuros atletas e incluir socialmente milhares de pessoas, já que o esporte tem um grande poder de transformação" (Disponível em: <http://www.cpb.org.br/>. Acesso em: 29 nov. 2015). Isso aponta a forte vinculação discursiva entre esporte, formação e pedagogia corporal em nossa sociedade.

Práxis Educativa, Ponta Grossa, v. 12, n. 2, p. 536-550, maio/ago. 2017 Disponível em: <http://www.revistas2.uepg.br/index.php/praxiseducativa > 
modelos. Um deles seria a incorporação tecnológica no corpo dos atletas, dada principalmente pelo alto nível de treinamento. Uma segunda possibilidade, que discutimos a seguir, mais para colocar a problemática do que para resolvê-la, diz respeito à dimensão estética presente nas competições esportivas, dada, por vezes, pela beleza corporal, pela técnica apurada e pela performance, algo que vem ganhando importância nos discursos contemporâneos.

\section{(D)eficiência, estética e incorporação tecnológica}

O Esporte tem se tornado um fenômeno tão abrangente que dimensões de sua prática antes não tão discutidas vêm se apresentando agora como importantes temas de pesquisas. Uma possibilidade é a estética. Vários autores têm se dedicado a investigar como esse conceito e essa experiência se fazem presentes no Esporte - se está na beleza dos gestos técnicos bem executados, na graça e na força dos corpos esculpidos, na linguagem esportiva expressa nos gestos que levam a um bom resultado, ou ainda na presença do grotesco nas práticas.

Entendemos que a dimensão estética traz algo mais para o esporte e, também, para sua presença na escola, para além de uma funcionalidade ou finalidade externa, o que agrega um valor formativo a esse tema que se mostra como conteúdo central da Educação Física Escolar. Assim, é importante pensar o esporte como conteúdo "[...] na sua complexificação, [que] significa desconstrui-lo e reconstrui-lo como conhecimento a ser trabalhado nas aulas de educação física" (VAZ, 2010, p. 103, grifos do autor), reconhecendo que pode haver na prática do fenômeno algo de fim em si mesmo, seja na beleza presente no gesto, ou na execução bem realizada que logo desaparece sem que necessariamente leve a um resultado efetivo.

Um dos autores que nos ajuda a pensar tal dimensão é Hans Ulrich Gumbrecht, que entende o esporte como objeto de desfrute e prazer ao ser assistido. Para ele, essa prática é "“...] um fenômeno que paralisa os olhos, algo que atrai constantemente, sem indicar nenhuma explicação para a atração" (GUMBRECHT, 2007, p. 20). O autor analisa o esporte a partir do que chama de cultura da presença que se preocupa em encontrar o valor das coisas mesmas, sem que haja procura por finalidades nela presentes. Por isso, Gumbrecht (2001) volta-se aos esportes e o que ele chama de eventos de epifania, capazes de produzir presença e intensidade por um breve momento em que a jogada ocorre. Assim, haveria a suspensão da realidade presente e outra seria produzida. Para Gumbrecht (2010), o espetáculo esportivo, como fenômeno estético, produz presença por meio de sua epifania, gerando eventos que são inesperados e únicos, que depois de produzidos não voltarão a ocorrer, desse modo provocando fascinação. Este seria, então, o resultado da tensão entre a efemeridade da presença e a consciência desse fenômeno ser único e singular. Para o autor, esse estado epifânico permite que tanto espectador quanto artista/jogador estejam em sintonia com as coisas do mundo. Em um momento em que estamos saturados de sentidos, as artes e os esportes teriam o poder de oferecer outra possibilidade de estar no mundo que não seja permeada pela constante procura de uma essência e um significado. Segundo Gonçalves (2014):

Para Gumbrecht, assistir esportes corresponde à definição kantiana de experiência estética, pois o belo, que advém de um juizo de gosto, considerado como aquela "satisfação pura e desinteressada" por um objeto, parece encontrar lugar privilegiado nesse contexto. Isso porque, neste caso específico, o termo "desinteresse" é destacado, na medida em que há uma desconexão entre a prática esportiva e o cotidiano, o que corresponderia, nos termos do autor, à autonomia ou insularidade da experiência estética. (GONÇALVES, 2014, p. 62).

Para o autor, essa fruição, além de impactar o espectador fã de esportes, também poderia ocorrer com os atletas, já que, no momento de uma jogada bonita, ou do prazer da disputa, eles

Práxis Educativa, Ponta Grossa, v. 12, n. 2, p. 536-550, maio/ago. 2017 Disponível em: <http://www.revistas2.uepg.br/index.php/praxiseducativa $>$ 
poderiam se desligar da multidão ao seu entorno, dos outros competidores e até mesmo dos resultados do evento esportivo do qual participam, de modo que as experiências de praticantes e espectadores aproximar-se-iam pela beleza da jogada ou da execução do movimento, estando próximo daquilo que Kant insistiu em chamar de desinteresse. Aquele que emitisse um juízo estético estaria desconectado das opiniões do mundo que o cerca e, nesse caso, o atleta, no momento da jogada, poderia partilhar da mesma sensação. Assim aconteceria o que Gumbrecht chama de "perder-se na intensidade da concentração" (GUMBRECHT, 2007, p. 45).

Por outro lado, não somente para o atleta, mas também para o espectador, em uma experiência estética com o esporte que o fascina, para além do resultado, é o que se coloca no momento da performance e o ato de julgá-la: "São movimentos corporais quase sempre já moldados pelas expectativas e pelo apreço que os espectadores levam com eles para o jogo" (GUMBRECHT, 2007, p. 109). Gumbrecht (2007) "[...] utiliza o conceito de fascínio para denominar o que ocorre com aquele que assiste esporte, já que ele trataria, por um lado, do olhar atraído e paralisado pelo apelo da performance atlética, captando, por outro, a dimensão adicional da contribuição do espectador" (GONÇALVES, 2014, p. 66) ${ }^{11}$.

Colocamo-nos a refletir como a questão da estética do corpo "anormal" aparece no esporte paralímpico, a partir dos fascinios que Gumbrecht aponta. Destacamos dois deles que nos parecem importantes para pensarmos sobre esse fenômeno. O primeiro seria a beleza presente nos corpos esculturais dos atletas, moldados pelo treinamento, tornando-os capazes de performances graciosas, procurando analisar como isso está colocado para os corpos com deficiência. Para tal, analisamos algo das representações do nadador Talisson Glock. Em segundo lugar, a simbiose entre os equipamentos utilizados nos esportes com os corpos dos atletas, não aqueles como a raquete no tênis ou as argolas na ginástica, mas sim, por exemplo, as próteses utilizadas no atletismo, pois é necessária uma íntima associação entre o objeto técnico externo e o atleta para que se obtenha bons resultados.

A técnica e o treinamento aplicados no corpo visam a performance e os bons resultados. Um corpo mais dominado, mais treinado e mais adaptado ao equipamento pode proporcionar mais rendimento. Se a eficiência e o bom resultado são a finalidade, já que vencer é o objetivo nos esportes, mais que produzir beleza, interrogamo-nos sobre a possibilidade de uma eficiência aplicada aos deficientes. É preciso, pois, reconhecer que essa incorporação dos atletas paralímpicos no esporte desperta a ideia de uma eficácia também daqueles que não seriam o exemplo dela (o esporte supõe a "eficiência" e não a "deficiência"). Desse modo, podemos pensar que, por vezes, a beleza apreciada nos esportes não está apenas na execução perfeita de um gesto técnico, mas também na eficiência que gera o resultado esperado. Para o corpo não deficiente tal hipótese talvez seja mais visível, visto que impera no esporte o código vitóriaderrota. Para o corpo deficiente ${ }^{12}$, essa condição apresentar-se-ia de maneira ainda mais decisiva, pois a chegada de um atleta que não possui as pernas ou que não enxerga, mas que termina a

\footnotetext{
11 São sete os fascínios apontados pelo autor: 1) os corpos dos atletas, corpos esculturais que realizam feitos pouco comuns entre os "simples mortais"; 2) o sofrimento presente nas disputas, a aproximação com a morte; 3) a graça caracterizada pelo distanciamento dos movimentos corporais em relação à consciência; 4) os instrumentos utilizados em alguns esportes e sua relação simbiótica com o corpo, podendo ser eles animais ou máquinas; 5) as formas realizadas pelos corpos, em especial em modalidades consideradas estéticas; 6) as jogadas realizadas nos esportes com bola, mais precisamente a forma dessas jogadas; 7) o timing dos atletas durante a contenda esportiva, aquela capacidade de fazer movimentos certos no momento certo (GUMBRECHT, 2007).

12 Embora pudéssemos empregar a expressão "pessoa com deficiência”, neste momento preferimos corpo deficiente, pois nos referimos a este, como tal, para o esporte, ou seja, um corpo que não é instrumentalizado com a mesma eficiência de um corpo esportista não deficiente.
}

Práxis Educativa, Ponta Grossa, v. 12, n. 2, p. 536-550, maio/ago. 2017 Disponível em: <http://www.revistas2.uepg.br/index.php/praxiseducativa > 
prova em primeiro lugar, poderia representar a beleza na eficiência, comparando-se com aqueles que atingem os mesmos resultados não possuindo uma deficiência.

Rendimento e eficiência são proporcionados pelo avanço técnico e tecnológico que, se, por um lado, indica que as pessoas com deficiência são incompletas e pouco eficientes para o esporte convencional; por outro, permitem que os corpos desses atletas possam ser vistos, pelo menos em alguns casos, não como deficientes, mas sim como super-corpos - fortes e ágeis dada a exigência do treinamento e a incorporação tecnológica. Assim, podem ser considerados super-homens e admirados da mesma forma que os atletas dos esportes convencionais. Ou, ainda mais, já que essa incorporação tecnológica possibilita quebra de recordes e grandes índices, algo dificilmente conseguido para os corpos não atletas, mas também não deficientes.

A partir do exposto, interrogamo-nos se há uma beleza na eficiência, para além daquela que observamos em um drible no futebol ou em um salto incrível de ginástica. Como pergunta Gumbrecht (2001, s/p), “[...] não terá alcançado a performance do futebol, na história recente, um nível de perfeição física que, embora admirável em e por si mesma, acabe sendo prejudicial a seu valor estético?”. O autor tem em vista algo como o jogo absolutamente técnico, com passes precisos e bem executados que acabam por resultar no gol e, consequentemente, na vitória, diferentemente da experiência mais imprevisível, com lances não esperados que proporcionam beleza/performance, mas não necessariamente a vitória. Entretanto, é interessante lembrar que, por vezes, apenas aquele que domina completamente a técnica é capaz de produzir desempenhos admiráveis, pois tem amplo comando corporal e pode realizar o não esperado.

Autores como Bertling e Schierl (2008) criticam a posição de Gumbrecht. Aqueles destacam que este propõe que a sociedade moderna testemunhou um aumento considerável na importância de uma assim chamada "cultura de presença". Gumbrecht (2007) argumenta que, em um mundo que constantemente sobrecarrega os sentidos humanos, existe a necessidade de criar um espaço no qual a sensação de liberdade completa possa se desdobrar. Essa possibilidade o autor vê facilitada em grande medida pelo esporte de alto rendimento, pois Gumbrecht (2007) afirma que o esporte nos permite observar corpos aparentemente em completa realização de movimentos específicos, em que há possibilidade de uma fruição sem interesse: "Entre esses movimentos, entre o olhar do jogador e a sua percepção, o mundo volta ao ritmo normal, e você respira fundo, o peito quase estourando de tão aliviado, tão orgulhoso e tão esperançoso, depois da bela jogada que já desapareceu e que nunca mais se repetirá em tempo real" (GUMBRECHT, 2007 , p. 23). O que está em jogo para o autor para além das vitórias, derrotas e recordes é o que ele chama de "[...] objeto dessa experiência, pertencente a uma série de fenômenos que fica de algum modo entre a performance e o ato de julgá-la" (GUMBRECHT, 2007, p. 108), fruto dos fascínios já discutidos anteriormente, "[...] em que o olhar é atraído - e até paralisado - pelo apelo de algo que é percebido (em nosso caso a performance atlética)” (GUMBRECHT, 2007, p. 109).

Os autores antes citados, porém, argumentam que Gumbrecht concentrou-se unicamente na beleza dos corpos perfeitos, empregando um conceito muito estreito da estética, enfatizando o apelo estético do corpo e da cultura da presença apenas no esporte de alto rendimento:

Principalmente nós queremos perguntar: como o que acontece em relação à beleza e à
experiência da beleza quando lidamos com um esporte que não tem apelo estético
(tornando, então, a desejada liberdade de sensação impossível)? Esses esportes tornam-
se desvalorizados? O que acontece quando, precisamente, imperfeição e não a beleza
está em primeiro plano? (BERTLING; SCHIERL, 2008, p. 40, tradução nossa). ${ }^{13}$

${ }^{13}$ No original: "Primarily we want to ask how what happens in respect to beauty and the experience of beauty when we deal with a sport that has no aesthetic appeal (thus making the desired freedom of sensation impossible)? Do

Práxis Educativa, Ponta Grossa, v. 12, n. 2, p. 536-550, maio/ago. 2017 Disponível em: <http://www.revistas2.uepg.br/index.php/praxiseducativa > 
Para Bertling e Schierl (2008), os corpos “imperfeitos" podem ser estética e performaticamente agradáveis. Desse modo, os autores questionam se não seria possível ampliar o conceito de estética utilizado por Gumbrecht, produzindo uma perspectiva que considerasse o esporte para um corpo deficiente e que, da mesma maneira, fosse considerado esteticamente agradável e enaltecido nos discursos sobre beleza atlética. Os autores reforçam que o tratamento destinado às Paralimpíadas passa sempre pelo enaltecimento da inclusão ou ainda da eficiência, já a beleza é um conceito que não se faz presente.

Um desses exemplos pode ser o do já citado nadador olímpico, Talisson Glock, que: "Bonito, tatuado e vencedor: Talisson Glock vira menino de ouro do Comitê Paralímpico Brasileiro (CPB)" (REBELLO, 2015, s/p) e tornou-se o rosto estampado nas propagandas dos Jogos Paralímpicos 2016. Um dos símbolos da nova geração de atletas e sua imagem, para além de suas chances de medalha, tem sido utilizado para, segundo o CPB, "[...] diversificar e ampliar ainda mais o público que acompanha as Paralimpíadas". Nas palavras do CPB: "Um rapaz bonito, vencedor e simpático é justamente a imagem que o movimento quer transmitir: qualquer um pode ter uma deficiência e se sobressair positivamente em diversas áreas e aspectos" (REBELLO, 2015).

O nadador, com 20 anos, de cativante sorriso, com o braço e a perna esquerda amputados após um acidente com um trem na infância, chama atenção pela beleza corporal e também pelo modo como adorna seu corpo. A pele foi sendo coberta aos poucos por tatuagens. Já envergou dois piercings, mas, atualmente, mantém apenas o da língua. Glock afirma que seu visual por vezes choca, mas ele diz não se importar com os comentários:

\begin{abstract}
Sou vaidoso. As primeiras tatuagens fiz por significado, mas depois passei a achar isso bobagem e fazer pela arte. Eu adoro, acho que não vou conseguir parar mesmo com a manga completa. O retorno que me dão sinceramente acho que é mais negativo do que positivo referente a isso, mas eu simplesmente não ligo. Se eu nadar rápido é suficiente e não vão questionar se eu tenho tatuagem ou não. (REBELLO, 2015, s/p).
\end{abstract}

Entretanto, na visão do presidente do $\mathrm{CPB}$, Andrew Parsons, a imagem corporal de Talisson impressiona positivamente, tanto no aspecto da utilização de sua beleza corporal, quanto em relação a seu rendimento, pois o nadador tem "[...] o potencial enquanto marca para manter o Brasil como referência no movimento paralímpico" e utiliza a representação do atleta para dar repercussão ao evento:

Todo movimento esportivo quer ter seu galã, sua atleta bonita, e ele cumpre bem esse papel, além da personalidade dele. É um menino ótimo, bem-humorado. É bacana ter um atleta paralímpico que não tem braço, perna, mas que tem esse estilão, boa pinta. Como ele se inspirou um dia em outros atributos no Daniel Dias, no Clodoaldo, ele faz parte dos nossos planos. Se no Rio ele não medalhar ouro, vai vir muito forte para Tóquio. Mas já é visível que a gente começou a divulgar um pouco mais o Talisson porque ele tem esses atributos que são importantes na carreira de qualquer atleta. (REBELLO, 2015, s/p).

Somada à discussão anterior, entendemos que a eficiência e a técnica, para além de construírem super-corpos para o esporte, forjam também uma estética dessa anormalidade, um espetáculo que possa ser assistido e que tenha o seu lugar. Fora desse espaço, talvez continuem sendo os corpos abjetos e diferentes, incluídos entre si mesmos, e que, durante a competição, treinados e dominados, também produziriam beleza, mas, fora dela, continuariam a ser aquilo que os adjetiva: apenas corpos deficientes. Entretanto, se consideramos as assertivas de Bertling e

such sports become devalued? What happens when, precisely, imperfection and not beauty is foregrounded?" (BERTLING; SCHIERL, 2008, p. 40).

Práxis Educativa, Ponta Grossa, v. 12, n. 2, p. 536-550, maio/ago. 2017 Disponível em: <http://www.revistas2.uepg.br/index.php/praxiseducativa > 
Schierl (2008), de uma mudança nos discursos endereçados a esses atletas, distanciando do binômio inclusão/superação, eles também poderiam ser admirados fora do evento esportivo, se vencem as competições, e se esta os produz como belos. Isso permitiria que o corpo desviante, anormal transpusesse o limiar desses eventos e adentrasse a vida cotidiana. Isso configuraria o que Novaes (2007 apud GONÇALVES; ALBINO; VAZ, 2009) chama de:

[...] um espetáculo específico ao proporcionar àqueles que visitam o território paradesportivo a presença de um espaço próprio de uma estética da anormalidade. Estética que não se pensa como um fim em si mesma, mas como produção/produtividade, no caso dada pelo esporte. As histórias de corpos diferentes, suprimidos, expulsos dos espaços culturais hegemônicos, remetem-nos a lugares proibidos, ora maculados pela piedade, ora escondidos pelas sombras das forças estéticas da normalidade. (NOVAES, 2007, p. 169 apud GONÇALVES; ALBINO; VAZ, 2009, p. 154).

Parece-nos, a partir do que Gumbrecht $(2001,2007)$ nos aponta, que os corpos dos atletas, paralímpicos ou não, podem produzir beleza, esteja ela presente nos gestos ou ainda na modelagem corporal, de modo a serem admirados e cultuados. Entretanto, essa beleza presente na eficiência ou apenas no corpo belo é produzida por um intenso treinamento, um amplo domínio que toma o corpo como um objeto a ser "trabalhado" por meio da técnica, produzindo os atletas que assistimos correr, saltar e jogar. Isso conforma uma tecnologia corporal que acaba por aproximar o corpo paralímpico do olímpico, algo que discutimos a seguir.

\section{Jogos Paralímpicos e Olímpicos: uma aproximação tecnológica}

Ao entendermos que a beleza e o rendimento estão colocados tanto para o esporte Paralímpico quanto para o Olímpico, deparamo-nos com mais uma aproximação: o corpo é tomado como objeto de domínio pelo treinamento esportivo, principalmente pela incorporação tecnológica. Assim, merece atenção a possibilidade do que poderíamos chamar de uma aproximação entre atletas paralímpicos e aqueles que praticam o esporte convencional, por compartilharem certa incorporação tecnológica. As competições esportivas de alto nível têm demonstrado que os atletas do esporte olímpico fazem uso de substâncias e de técnicas que melhoram seu desempenho físico ${ }^{14}$, o que não os afasta, ao contrário, dos atletas paralímpicos. Dito de outra forma, o uso de implementos tecnologicamente desenvolvidos não é, evidentemente, exclusivo do paralimpismo, pelo contrário:

As competições esportivas para portadores de deficiência são uma metáfora, talvez antecipatória, talvez com imagem invertida, daquilo que pode ocorrer também no esporte de alto rendimento. Um tema que tem estado presente em fóruns de debate sobre questões filosóficas relacionadas ao esporte é a possível troca de um membro do corpo humano por uma peça construída artificialmente. Uma vez que um braço não

\footnotetext{
14 O mundo esportivo frequentemente é abalado quando o uso de substâncias ilícitas no esporte se torna manifesto. Um caso recente tornou-se público no dia 9 de novembro, quando um relatório de investigação de uma comissão independente da Agência Mundial Antidoping (WADA), apontou um sistema de dopagem institucionalizado na Rússia, envolvendo atletas, técnicos, oficiais de controle de doping, dirigentes da federação do país, integrantes do governo russo e até membros da Federação Internacional de Atletismo (IAAF). A participação dos russos das provas de atletismo das Olimpíadas de 2016 foi então colocada em dúvida. O Brasil, também com o atletismo, já sofreu com escândalos de doping. No mais eloquente deles, no ano de 2009, às vésperas do Mundial de Atletismo em Berlim, cinco atletas do extinto clube Rede Atletismo foram flagrados no exame antidoping e suspensos por dois anos. Bruno Lins, Jorge Célio, Josiane Tito, Luciana França e Lucimara Silvestre foram defendidos pelos técnicos Jayme Netto e Inaldo Sena e pelo fisiologista da equipe que assumiram a responsabilidade pelo incidente e foram banidos do esporte. Recentemente, foram reabilitados. Maurren Maggi é outra atleta que foi flagrada em um exame antidoping e teve de cumprir dois anos de suspensão, sendo impedida de participar dos Jogos Olímpicos de 2004, na Grécia, retornando depois do período de afastamento às pistas, e alcançando a medalha de ouro no salto em distância nos Jogos de Pequim em 2008.
}

Práxis Educativa, Ponta Grossa, v. 12, n. 2, p. 536-550, maio/ago. 2017 Disponível em: < http://www.revistas2.uepg.br/index.php/praxiseducativa > 
tenha a precisão adequada para um arremesso, ele poderá ser trocado por um outro, potencialmente melhor, eletrônico, controlado por computadores. A utilização de substâncias químicas que potencializam o desempenho (o doping) já é de certa forma uma expressão disso. Fica difícil condenar o doping se se permite que o corpo, de qualquer forma, seja reduzido a um objeto operacional, como é o que acontece, pelo menos até certo ponto, no treinamento desportivo. (VAZ, 1999, p. 105).

Esse uso indica a utilização de uma tecnologia química, talvez uma prótese química, em busca de um melhor desempenho nas pistas e nas quadras. Essa incorporação tecnológica parece aproximar as pessoas com e sem deficiência, embora ainda não seja permitido que possam competir juntas. Dessa forma, pode-se pensar o doping como uma espécie de prótese, da mesma forma que aquelas utilizadas pelos atletas paralímpicos, já que a prótese química, incorporada nos corpos dos atletas os ajuda a competir em melhores condições. Talvez, nesse caso, encontre-se uma antecipação dos Jogos Olímpicos do futuro, já que cada vez mais esse tipo de uso que melhora e permite a performance parece ser necessária, com limites cada vez mais flutuantes, em que pese o aparente acirramento - e as confusões - das normas contra o uso de determinadas substâncias. Ao analisar alguns escândalos de doping nas olimpíadas, Vaz (2005) discute o caso do americano Carl Lewis que, em 2003, foi notícia de jornais por ter supostamente ganhado várias medalhas olímpicas entre 1984 e 1996, tendo sido flagrado no teste antidoping entre os anos 1991 e 2000. Entretanto, como afirma Vaz (2005):

O que mais chama a atenção no caso de Lewis é a polêmica quanto à legitimidade do uso das drogas. Por um lado, pelas novas regras da Wada (Agência Mundial Antidoping) Lewis seria hoje apenas advertido (Folha de S. Paulo, 30 set. 2003, p. D-2), já que seus exames teriam apontado níveis permitidos na época (Folha de S. Paulo, 27 abr. 2003, p. D-7), o que teria levado as Federações Norte-americana e Internacional de Atletismo a não o punirem. (Folha de S. Paulo, 1 maio 2003, p. D-2, D-3). (VAZ, 2005, p. 29).

Aquele menos avisado, ou que conheça pouco o ambiente esportivo, pode se espantar ao perceber que as drogas parecem ser necessárias para o esporte, como seu uso é permitido ${ }^{15}$, “[...] sendo sua utilização um jogo entre o lícito e o ilícito, uma aposta no que é momentaneamente permitido, deslocando-se o eixo do legítimo para o legal" (VAZ, 2005, p. 34). O corpo dos atletas olímpicos moldados pelo treinamento exaustivo, pelos ciclos de periodização (BOMPA, 2002; WEINECK, 1999), são produzidos para a potência máxima, com limites que são constantemente superados, corpos que já não são - e nunca foram - naturais, forjados pela tecnologia, ficando impossível afirmar que haja algo neles de "natural" (como de resto no dos não atletas, já que somos resultado da cultura). Isso vale mesmo para aqueles que reivindicam uma pureza no esporte, já que o próprio treinamento assinala para uma desnaturalização do corpo. Para Silveira e Vaz (2014):

Segundo Haraway, "somos todos quimeras, híbridos - teóricos e fabricados - de máquina e organismo; somos, em suma, ciborgues" (2000:41), utilizando os aparatos tecnológicos que estão a nosso dispor. Já não estaria claro onde termina o humano e começa a máquina: "não existe, em nosso conhecimento formal, nenhuma separação fundamental, ontológica, entre máquina e organismo, entre técnico e orgânico" (Haraway, 2000:100). Dessa forma, a imagem do ciborgue pode contribuir para

\footnotetext{
15 Observe-se, por exemplo, o mais recente escândalo de doping, o da atleta russa Maria Sharapova, que, por dez anos, fez uso da substância Meldonium, antes permitida e que somente neste ano foi proibida, ocasionando o flagrante. Entretanto, a WADA informou que pode haver uma mudança na regra do exame relacionado ao Meldonium. De acordo com a agência, atletas que foram flagrados no exame poderão escapar de punição dependendo da quantidade da substância encontrada nas amostras coletadas. Disponível em: <http://esportes.terra.com.br/tenis/sharapovaanuncia-que-foi-pega-no-doping-durante-aberto-da-australia,c3def6b83e41275ec4ce000863f1 c364b2czf2at.html $>$.

Acesso em: 12 mar. 2016. E em: < http://olimpiadas.uol.com.br/noticias/2016/04/13/wada-relaxa-regras-demeldonium-e-atletas-podem-ser-liberados-de-doping.htm>. Acesso em: 13 abr. 2016.
}

Práxis Educativa, Ponta Grossa, v. 12, n. 2, p. 536-550, maio/ago. 2017 Disponível em: <http://www.revistas2.uepg.br/index.php/praxiseducativa $>$ 
rompermos com o dualismo corpo - natureza para a explicação dos corpos e suas expressões. Ser ciborgue refere-se também à frequência em academias de ginástica, à utilização de suplementos alimentares, roupas específicas, “inteligentes” e aerodinâmicas, e quaisquer aparatos que visem uma melhoria ou alteração na máquina humana. Nessa perspectiva, o doping pode ser entendido como uma tecnologia química a serviço do espetáculo, pois atua diretamente na performance atlética. (SILVEIRA; VAZ, 2014, p. 452).

O discurso da legalidade, das regras da mesma forma, aparece no esporte paralímpico, aproximando-o do olímpico. Para além do uso de drogas para aumento da performance, as próteses dos atletas também são alvo de investigação antes das disputas para não proporcionarem vantagem aos atletas. Oscar Pristorius, no ano de 2012, nas Paralimpíadas de Londres, quando perdeu a final dos 200 metros para o brasileiro Alan Fonteles, criticou o uso das próteses de seu adversário, que lhe teriam auferido benefício, com cinco centímetros a mais do que as próteses que utilizava nas competições anteriores. Fonteles cruzou a linha de chegada com o tempo de 21s45, à frente dos 21s52 do sul-africano. O treinador da equipe brasileira de atletismo, Ciro Winckler, confirmou que o paraense realmente estava mais alto, com $1.81 \mathrm{~m}$, contra $1.76 \mathrm{~m}$ no Mundial da Nova Zelândia, no ano de 2011. Na ocasião, Alan ficou com o bronze nos 100m e Pistorius com a prata. A mudança permitida pelas regras do Comitê Paralímpico Internacional foi criticada por Pristorius:

\begin{abstract}
Estou decepcionado. Fiz uma prova fantástica. Não acho que foi injusto, Alan jogou com as regras, mas ele nunca tinha corrido na casa dos 21 segundos. Isso é um fato. Ele fazia com dificuldade 23 há menos de um ano. Então, acho que devemos olhar apenas para os fatos do passado. Alan está jogando muito com as regras” (MOTA, 2012, s/p, grifos nossos).
\end{abstract}

O sul-africano esclareceu que seus questionamentos não foram a respeito da tecnologia utilizada, mas pelo aumento de cinco centímetros do Mundial da Nova Zelândia, em 2011, para as Paralimpíadas: "Não acho isso (ter sido injusto). Todos temos a mesma tecnologia, não há diferença neste sentido. Minha restrição é apenas por eles (Alan - ouro e Blake Leeper - bronze) se tornarem maiores nos últimos meses. Isso que temos que olhar" (MOTA, 2012, s/p). É interessante notar que as próteses que ambos os atletas usam são do mesmo modelo, de fibra de carbono pesando menos de 3 quilos em conjunto. Pristorius afirmou, na época, que, com $5 \mathrm{~cm}$ a mais, a passada de Alan teria se tornado muito ampla. Entretanto, a análise da prova demonstra que Fonteles deu 98 passos para chegar a linha de chegada com passadas de, em média, aproximadamente dois metros. Já Pristoirus deu 92, com dois metros e vinte centímetros por passada, ou seja, mais ampla que a de Fonteles (MOTA, 2012). Este respondeu apenas: "Não tenho o que falar. Estou dentro das regras. Isso que eu tenho que dizer" (MOTA, 2012, s/p).

Assim como no esporte olímpico, quando atletas usam drogas para estar em condições de competir, flutuando entre o permitido e o não permitido, atletas paralímpicos utilizam próteses de tamanhos diferentes, mas que são consentidas dentro da regra de cada esporte. Jogam, assim, com as regras. Da mesma maneira, os atletas sem deficiência fazem uso das regras para melhorar suas performances. É o caso dos supermaiôs de poliuretano, que, até serem proibidos, ajudaram no desempenho dos nadadores que alcançaram recordes mundiais até então impensáveis. Ao se perceber que essas vestimentas ofereciam vantagem considerada exagerada aos atletas, seu uso foi proibido, da mesma forma que algumas drogas que, inicialmente ausentes da lista de substâncias proibidas, podem, com o tempo, passar a compô-la, o que efetivamente acontece. Pristorius utilizou o mesmo discurso que, contra si, fora destinado quando tentou correr nas Olimpíadas - que suas próteses lhe confeririam vantagem, da mesma forma que as de Fonteles.

Um caso semelhante é o do alemão Markus Rehn. As próteses que ele utiliza para saltar são cinco centímetros maiores que as do dia a dia. Ele, assim, se coloca sobre o tema:

Práxis Educativa, Ponta Grossa, v. 12, n. 2, p. 536-550, maio/ago. 2017 Disponível em: <http://www.revistas2.uepg.br/index.php/praxiseducativa> 
Há toda uma discussão sobre as próteses. Há um limite de tamanho. No meu caso, a prótese que uso para saltar é maior do que a para caminhar. Há uma discussão se realmente há um avanço. Dados estão sendo coletados, e testes realizados. Vamos chegar a um momento em que vamos chegar à prótese considerada igual. (KESTELMAN, 2016, s/p).

Claramente, Markus utiliza próteses que melhoram seu desempenho nas pistas, mas o faz dentro das regras, sugerindo uma extrema simbiose entre homem e máquina, já que a adaptação a próteses de tamanhos diferentes parece requerer uma grande capacidade de ajuste. Importante ressaltar que, o que parece limitar a participação de um atleta paralímpico ou não, para além de sua performance, talvez seja a sua capacidade de incorporação tecnológica, química ou física e não apenas seu desempenho.

Para além de discussões biológicas e médicas, a incorporação tecnológica parece indicar um problema moral nos esportes paralímpico e olímpico, que se relaciona a uma suposta pureza presente no fenômeno. Pensemos, por exemplo, na negativa de competirem gêneros distintos na mesma prova e no constante controle dos hormônios feito nos corpos dos atletas para que nenhum possa estar fora da normatividade imposta para o feminino e para o masculino, o que feriria a suposta igualdade formal de chances. Nesse caso, o doping feriria os preceitos heterossexuais do esporte e, também, deixaria as mulheres que fazem uso de substâncias dopantes mais fortes e mais ágeis, podendo produzir um corpo mais apto para a competição, mais próximo do gênero masculino e em condições de superioridade frente as outras mulheres.

Relacionamos a utilização de substâncias químicas à produção de um corpo atleta (doping feminino) por considerar que a presença corporal que foge do padrão heterossexual feminino representa uma ameaça à ordem social dominante. A utilização do doping pelas atletas causa incômodo, principalmente, pelos efeitos que essas substâncias podem ter sobre a feminilidade convencional, que passa a ser relacionada diretamente com o efeito de masculinização. (SILVEIRA; VAZ, 2014, p. 456).

Somada a esse fato, está sempre a questão de uma aura que está circunscrita aos atletas que não devem nunca ser vistos fumando ou usando substâncias ilegais para não "degenerarem" a prática esportiva. Algo bem questionável se levarmos em consideração o uso de substâncias que melhoram o desempenho esportivo ou, ainda, os colocam em condições de competir novamente após alguma lesão, usados contemporaneamente pelos atletas de alto rendimento. Esse controle, esse domínio que possibilita essa aura e essa pureza ao esporte e aos atletas, e do qual o primeiro parece que não pode prescindir, também está colocado para o esporte paralímpico.

\section{Considerações finais}

Ao nos debruçarmos sobre o esporte paraolímpico, tentamos perceber como essa expressão corporal nos ajuda a entender os processos presentes nas competições esportivas, seja o protagonismo do corpo, dada sua mecanização; seja a beleza presente ou produzida pela performance; os discursos sobre superação e inclusão construídos sobre o fenômeno; ou a aproximação entre a versão paralímpica e olímpica do esporte.

Ao procuramos compreender elementos de uma possível estética colocada para os corpos deficientes, deparamo-nos com a possibilidade de observar a beleza na eficiência. É possível indicar, nesse caso, que a estética no esporte paralímpico, por vezes, não diz respeito necessariamente àquilo que é belo para ser fruído, mas sim ao resultado, ao gol, ao que funciona, assim como acontece no esporte convencional. Desse modo, a beleza das práticas dos esportes para pessoas com deficiência, para além dos corpos esculturais e performáticos - que também

Práxis Educativa, Ponta Grossa, v. 12, n. 2, p. 536-550, maio/ago. 2017 Disponível em: < http://www.revistas2.uepg.br/index.php/praxiseducativa > 
estão presentes, mas nunca deixam de ser apontados como anormais -, pode estar relacionada a uma funcionalidade, mesmo para aqueles que parecem estar menos aptos para ela.

Também nos parece importante dizer que afirmar que o corpo deficiente se coloca menos preparado para o treinamento seria uma simplificação. Diferentemente dos atletas não deficientes - que também modificam seu corpo pelo treinamento, mas não podem ser flagrados no uso de substâncias químicas, talvez como chamamos, próteses químicas que melhorem seu desempenho os atletas paralímpicos são uma espécie de homem-máquinas regulamentados que podem modificar seu corpo com o artifício da prótese que melhora seu desempenho, sem estarem em desacordo com as regras, já que próteses para o dia a dia e as para competir são diferentes, com destaque para a altura. É importante lembrar, porém, que a prótese química também é vedada a esses atletas, o que nos permite afirmar que, assim como algumas substâncias são permitidas, outras não, certas próteses são legais, outras não. Encontra-se aí um movimento complexo que aponta que apenas algumas das mesclas entre ser humano e instrumentos técnicos são legais.

Os discursos construídos sobre o esporte paralímpico aproximam-se, já que fazem parte do mesmo fenômeno, daqueles de sua versão olímpica. Entretanto, para o primeiro está colocada a ideia de que este não seria naturalmente o local desses corpos, já que sempre são adjetivados pela deficiência, emoldurados pela inclusão e pela superação, que, embora também esteja colocada para atletas olímpicos, ganha muito mais força no último. Dificilmente esses competidores são em primeiro lugar lembrados como atletas, como foi possível verificar na fala da atleta Rosinha dos Santos do atletismo do Brasil, antes sim como deficientes. Segundo o modelo que ainda impera, apenas como tais que devem ser observados, produzir beleza, angariar reconhecimento. Talvez seja o caso de produzir uma outra narrativa sobre eles, sem desconhecer-lhes as particularidades, mas reconhecendo-os como o que são: atletas.

\section{Referências}

BERTLING, C.; SCHIERL, T. Disabled sport and its relation to contemporary cultures of presence and aesthetics. Sport in History, v. 28, n. 1, p. 39-50, mar. 2008. DOI: $10.1080 / 17460260801889202$

BOMPA, T. O. Periodização: teoria e metodologia do treinamento. 4. ed. São Paulo: Phorte, 2002.

BROHM, J. M. (Org). Deporte, cultura y represión. Barcelona: Gustavo Gili, 1978.

GARRITANO, P.; RICHARD, I. Em Toronto, atletas paralímpicos querem mudar percepção sobre o esporte. EBC - Agência Brasil, Brasília, ago. 2015. Disponível em: $<$ http://agenciabrasil.ebc.com.br/geral/noticia/2015-08/em-toronto-atletas-paralimpicosquerem-mudar-percepcao-sobre-o-esporte>. Acesso em: 1 fev. 2017.

GONÇALVES, M. C. Esporte e estética: um estudo com jogadoras de rúgbi. 2014. 225 f. Tese (Doutorado em Educação) - Universidade Federal de Santa Catarina, Florianópolis, 2014.

GONÇALVES, G. C.; ALBINO, B. S.; VAZ, A. F. O herói esportivo deficiente: aspectos do discurso em mídia impressa sobre o Parapanamericano/2007. In: PIRES, G. de L. (Org.). “Observando" o Pan Rio/2007 na mídia. Florianópolis: Tribo da Ilha, 2009. p. 149-167. 
GUMBRECHT, H. U. A forma da violência - em louvor da beleza atlética. Folha de São Paulo, São Paulo, mar. 2001. Disponível em: <http://Www1.Folha.Uol.Com.Br/Fsp/Mais/Fs1103200105.Htm>. Acesso em: 2 fev. 2017.

GUMBRECHT, H. U. Elogio da beleza atlética. São Paulo: Companhia das Letras, 2007.

GUMBRECHT, H. U. Produção de presença: o que o sentido não consegue transmitir. Rio de Janeiro: Contraponto; PUC-Rio, 2010.

KESTELMAN, A. Amputado, alemão aguarda aval para "unir esporte" e disputar as Olimpíadas. Globo.com, Rio de Janeiro, fev. 2016. Disponível em: <ttp://globoesporte.globo.com/programas/verao-espetacular/noticia/2016/02/amputadoalemao-aguarda-aval-para-unir-esporte-e-disputar-olimpiadas.html>. Acesso em: 28 fev. 2016.

MARQUES, R. F. R. et al. Esporte olímpico e paraolímpico: coincidências, divergências e especificidades numa perspectiva contemporânea. Revista Brasileira de Educação Física e Esporte, São Paulo, v. 23, n. 4, p. 365-77, out./dez. 2009. DOI: 10.1590/s180755092009000400006

MEINICKE, T. Sem limites: a extraordinária força de vontade dos atletas paralímpicos para superar os obstáculos que os separam de uma medalha na Rio 2016. Revista Veja Rio, Rio de Janeiro, n. 40, p. 22-26, out. 2015.

MOTA, C. Com reação incrível, Alan desbanca Pistorius e arranca o ouro nos 200m. Globo.com, Rio de Janeiro, set. 2012. Disponível em: <http://globoesporte.globo.com/paralimpiadas/noticia/2012/09/alan-responde-criticas-depistorius-com-ouro-nos-200m-rasos-t44.html>. Acesso em: 12 jan. 2016.

REBELLO, H. Bonito, tatuado e vencedor: Talisson Glock vira menino de ouro do CPB. Globo.com, Rio de Janeiro, ago. 2015. Disponível em: <http://globoesporte.globo.com/parapan/noticia/2015/08/bonito-tatuado-e-vencedor-talissonglock-vira-menino-de-ouro-do-cpb.html>. Acesso em: 31 jan. 2017.

SILVEIRA, V. T.; VAZ, A. F. Doping e controle de feminilidade no esporte. Cadernos Pagu, Campinas, n. 42, p. 447-475, jan./jun. 2014. DOI: 10.1590/0104-8333201400420447

VAZ, A. F. Doping, esporte, performance: notas sobre os "limites" do corpo. Revista Brasileira de Ciências do Esporte, Campinas, v. 27, n. 1, p. 23-36, set. 2005.

VAZ, A. Jogos, esportes: desafios para a Educação Física Escolar. Cadernos de Formação RBCE, v. 1, p. 96-106, 2010.

VAZ, A. F. Treinar o corpo, dominar a natureza: notas para uma análise do esporte com base no treinamento corporal. Cadernos Cedes, Campinas, V. 19, n. 48, p. 89-10, ago. 1999. DOI: /10.1590/s0101-32621999000100006

WEINECK, J. Treinamento Ideal. 9. ed. Barueri: Manole, 1999.

Recebido em 01/05/2016

Versão corrigida recebida em 26/01/2017

Aceito em 03/02/2017

Práxis Educativa, Ponta Grossa, v. 12, n. 2, p. 536-550, maio/ago. 2017 Disponível em: <http://www.revistas2.uepg.br/index.php/praxiseducativa $>$ 